\title{
Differences in employment concerns between Hispanic and Caucasian persons with multiple sclerosis: A propensity score matching analysis
}

\author{
Phillip D. Rumrilla,*, Jennifer Sánchez ${ }^{\mathrm{b}, 1}$, Jia-Rung $\mathrm{Wu}^{\mathrm{c}, 2}$, Stuart Rumrill ${ }^{\mathrm{d}}$, Kanako Iwanaga ${ }^{\mathrm{e}, 3}$, \\ Jian $\mathrm{Li}^{\mathrm{f}}$ and Fong Chan ${ }^{\mathrm{d}, 4}$ \\ ${ }^{\mathrm{a}}$ University of Kentucky, Lexington, KY, USA \\ ${ }^{\mathrm{b}}$ The University of Iowa, Iowa City, IA, USA \\ ${ }^{\mathrm{c}}$ Northeastern Illinois University, Chicago, IL, USA \\ ${ }^{\mathrm{d}}$ University of Wisconsin-Madison, Madison, WI, USA \\ ${ }^{\mathrm{e}}$ Virginia Commonwealth University, Richmond, VA, USA \\ ${ }^{\mathrm{f}}$ Kent State University, Kent, OH, USA
}

Received 18 February 2020

Accepted 13 August 2020

\begin{abstract}
. MS-related variables. and personal-environmental resources related to work. are discussed.

Keywords: Multiple sclerosis, employment concerns, race/ethnicity

\footnotetext{
${ }^{1}$ Jennifer Sánchez https://orcid.org/0000-0001-8448-0678

${ }^{2}$ Jia-Rung Wu https://orcid.org/0000-0002-9155-8418

${ }^{3}$ Kanako Iwanaga https://orcid.org/0000-0002-3310-6253

${ }^{4}$ Fong Chan https://orcid.org/0000-0001-6254-6891

*Address for correspondence: Phillip D. Rumrill, University of
} Kentucky, Human Development Institute, 126 Graham Avenue, Lexington, Kentucky 40508, USA. Tel.: +1 330524 1598; E-mail: phillip.rumrill@uky.edu.
\end{abstract}

BACKGROUND: Little is known about the experiences and concerns of Hispanic Americans with multiple sclerosis (MS), especially how their experiences and concerns compare to those of Caucasian Americans with MS.

OBJECTIVE: The purpose of this study was to examine differences in satisfaction with the overall employment situation between two matched samples of adults with MS, namely, Hispanics and Caucasians.

METHODS: Participants in this study responded to a national survey of the employment and community living concerns of people with MS. A propensity score matching (PSM) procedure was used to match participants based on demographic and

RESULTS: A two-sample Hotelling $T^{2}$ test revealed no statistically significant between-group differences on satisfaction regarding fair treatment in the workplace but between-group differences were observed on satisfaction regarding legal rights

CONCLUSIONS: Implications for future research and clinical practice in rehabilitation counseling in the COVID-19 era

\section{Introduction}

Multiple sclerosis (MS) is well known to medical science as an emerging disability (Koch \& Rumrill, 2017) because of its sharply rising incidence and prevalence across the globe. As many as 1 million 
Americans are currently living with this demyelinating auto-immune disease. Long considered a chronic health condition primarily affecting people of European lineage in the Northern Hemisphere, MS is now known to occur in all ethnic groups, with recent evidence documenting an increasing number of cases in Latin America (National Multiple Sclerosis Society [NMSS], 2019). Although many similarities exist between Hispanic Americans with MS and European Americans with MS, some differences have been identified. The etiology and progression of MS is thought to follow the same structure for Hispanics and Caucasians. According to Amezcua (2014), Hispanic Whites and Non-Hispanic Whites report similar types and constellations of symptoms, all of which are primarily determined by the size and locations of demyelinating lesions that the disease causes in the brain and on the spinal cord. In terms of the course of the disease, as with European Americans with MS, the largest percentage of Hispanic Americans with MS fall into the relapsing-remitting category, followed by the secondary progressive classification (Rivera \& Landero, 2005).

In terms of disparities, the U.S. incidence of MS among Hispanics is increasing faster than the incidence of MS among Caucasians (Murray, 2016). Age at onset of MS symptoms and age at diagnosis are slightly lower among Hispanics (Amezcua, 2014), which means that Hispanics with MS will be coping with MS for longer periods of time throughout their work lives than will their Caucasian counterparts. Much of the extant research on MS and employment has focused on people of European descent who acquire the disease. Very little is known about the experiences and concerns of people with MS from traditionally underrepresented racial and ethnic minoritized groups (e.g., African Americans, Hispanic Americans), especially how their experiences and concerns compare to those of Caucasians with MS, even though evidence indicates that the incidence of MS is increasing among non-Caucasians worldwide (Buchanan et al., 2011; Cristiano et al., 2013; Rivera, 2009; Rivera-Olmos \& Ávila, 2007).

Preliminary studies of the employment issues facing Hispanics with MS indicate that these individuals have a lower rate of labor force participation and a lower rate of job satisfaction than do Caucasians with MS (Roessler et al., 2016). However, the extant MS literature does not include a systematic comparison of the specific employment concerns of people with MS across the two racial/ethnic groups, nor does it include studies that have systematically controlled for important demographic and disease-related covariates that influence employment experiences and outcomes. Given the fact that our limited knowledge of the disease experiences of Hispanics with MS already suggests some differences in comparison to the experiences of Caucasians, and also given the fact that Hispanics with MS have not been systematically compared to Caucasians with MS in terms of their employment experiences (although the rate of labor force participation is troublingly low for both groups), the important question asked by Vickers (2012, p.177), "What is life and work life really like for a person with MS?" should be extended to "What is life and work life really like for Hispanics with MS, and how do life and work experiences differ for Hispanics with MS in comparison to Caucasians with MS?"

\subsection{Purpose of the present study and research question}

The purpose of this study was to examine racial/ ethnic differences in satisfaction with employment issues related to fair treatment, personal-environmental resources, and legal rights within a national sample of Hispanics and Caucasians with MS. The need for this study is underscored by the fact that much of the research-based knowledge on the impact of MS on employment relies on investigations in which the vast majority of participants are European American. For example, the percentages of participants of European extraction in MS employment-related research range typically from about $75 \%$ to $100 \%$ (Bishop et al., 2013; Chiu et al., 2013; Fraser et al., 2009; Julian et al., 2008; Rumrill et al., 1999; Smith \& Arnett, 2005). Hence, information in this study is valuable because it is derived from matched sub-samples of Hispanics and Caucasians with MS, meaning that the same number of people in each racial/ethnic group were included in the present analysis.

The following research question guided the study: What differences exist between Hispanics with MS and Caucasians with MS in terms of their satisfaction with employment issues related to fair treatment, personal/environmental resources, and legal rights? The present study compared satisfaction ratings on 17 key employment issues within a national sample of people with MS who were divided into two matched sub-samples following a propensity score matching (PSM) procedure to answer the research question. 


\section{Method}

Data for this study were collected from a survey of the employment concerns of adults with MS from nine NMSS chapters in the United States (Rumrill et al., 2015). The survey elicited information regarding the demographic, disease-related, and social and environmental participation variables pertinent to the overall employment situation for Americans with MS.

\subsection{Participants}

A total of 1,351 Hispanic and Caucasian participants formed the present study sample. Participants ranged in age from 19 to 96 years old with an average age of $53.47(S D=11.79)$. The average age at MS onset was $37.16(S D=10.17)$. Approximately half of the participants were within the prime working age range $(n=668,49.4 \%)$, with $31.4 \%$ being employed full-time $(n=422)$ and $12.1 \%$ being employed part-time $(n=162)$. The majority of participants were female $(n=1063,78.7 \%)$ and the overall sample was relatively highly educated (48\% held bachelor's degrees or higher, $27.8 \%$ had completed community/vocational/technical college, and $24.3 \%$ had less than a high school diploma). Frequently reported MS symptoms were as follows: fatigue (indicated by $79.4 \%$ of the sample), balance/ coordination problems (64\%), diminished physical capacity $(62.5 \%)$, gait/mobility impairment (56.1\%), tingling (53.5\%), numbness (50.1\%), cognitive impairment (50\%), bowel or bladder dysfunction (49.6\%), spasticity (44\%), pain (41\%), sleep disturbance (35.4\%), depression (32.9\%), vision problems $(31.2 \%)$, and anxiety (27.6\%).

\subsection{Instrument}

The Satisfaction with Employment Issues Scale developed by Merchant et al. (2019) was used as the dependent variable in the present study. It is comprised of 17 items and three subscales: (a) Fair Treatment (e.g., "People with MS are evaluated no more frequently than other workers"); (b) Environmental/ Personal Resources (e.g., "People with MS have access to assistive technology resources needed for work"); and (c) Legal Rights (e.g., "People with MS know what to do if they encounter discrimination at work"). See Appendix A for a list of all 17 items, grouped according to their sub-scales. Each item is rated on a binary satisfaction scale $(0=N o$,
$1=$ Yes). Items for each sub-scale were averaged to yield an item mean score, with higher scores indicating greater degrees of satisfaction. In the Merchant et al. 2019 study, the internal consistency reliability coefficients (Cronbach's alphas) were computed to be $0.98,0.96$, and 0.98 for the Fair Treatment, Environmental/Personal Resources, and Legal Rights sub-scales, respectively. In the present study, the Cronbach's alpha coefficients were computed to be 0.85 for Fair Treatment, 0.88 for Environmental/ Personal Resources, and 0.92 for Legal Rights.

\subsection{Procedure}

This study represented a secondary data analysis based on a national survey of the employment concerns of Americans with MS conducted by Rumrill et al. (2015) with funding from the NMSS. Data were collected from nine NMSS chapters across the United States (Rumrill et al., 2015). The aim of sampling for the overall survey was to ensure that participants were representative of the total population of people with MS with regard to geographic location, gender, race/ethnicity, income, and education. Of the 7,369 people with MS whom Rumrill et al. (2015) included in the target sample, 1,932 people returned questionnaires, resulting in a response rate of $26 \%$. A total of 1,844 members of the original respondent sample provided complete information on the above-mentioned 17-item Satisfaction with Employment Issues Scale (Merchant et al., 2019). From this group of complete responders, we extracted 1,351 Hispanic and Caucasian persons with MS for the present study.

\subsection{Statistical analysis}

Eight prominent demographic predictors were used for the PSM analysis (i.e., prime working age, gender, marital status, education, course of MS, MS severity, financial situation, and health status), which utilized logistic regression analysis and the nearest neighbor method. The propensity score computed for each Hispanic person was used to locate a Caucasian person with a similar propensity score. The Hispanic group and the matched Caucasian group were compared on three dependent variables (i.e., fair treatment, personal-environmental resources, and legal rights). Researchers used the two-sample Hotelling $T^{2}$ test for the between group comparisons on the three dependent measures. 
Table 1

Comparison of Caucasian and Hispanic participants before and after matching

\begin{tabular}{|c|c|c|c|c|c|}
\hline \multirow[b]{2}{*}{ Demographic variables } & \multirow[b]{2}{*}{$\begin{array}{l}\text { Hispanic } \\
(n=163)\end{array}$} & \multicolumn{2}{|c|}{ Before matching $(N=1351)$} & \multicolumn{2}{|c|}{ After matching $(N=326)$} \\
\hline & & $\begin{array}{l}\text { Caucasian } \\
(n=1188)\end{array}$ & $p$ level & $\begin{array}{c}\text { Caucasian } \\
(n=163)\end{array}$ & $p$ level \\
\hline \multicolumn{6}{|l|}{ Prime working age } \\
\hline Yes & $110(67.5 \%)$ & $558(47.0 \%)$ & $X^{2}(1, N=1351)=24.13$ & $105(64.4 \%)$ & $X^{2}(1, N=326)=0.34$ \\
\hline No & $53(32.5 \%)$ & $630(53.0 \%)$ & $p<0.0001$ & $58(35.6 \%)$ & $p=0.56$, n.s. \\
\hline \multicolumn{6}{|l|}{ Gender } \\
\hline Female & $123(75.5 \%)$ & $940(79.1 \%)$ & $X^{2}(1, N=1351)=1.15$ & $124(76.1 \%)$ & $X^{2}(1, N=326)=0.01$ \\
\hline Male & $40(24.5 \%)$ & $248(20.9 \%)$ & $p=0.31$, n.s. & $39(23.9 \%)$ & $p=0.90$, n.s. \\
\hline \multicolumn{6}{|l|}{ Marriage status } \\
\hline Married & $87(53.4 \%)$ & $841(70.8 \%)$ & $X^{2}(1, N=1351)=20.22$ & $91(55.8 \%)$ & $X^{2}(1, N=326)=0.20$ \\
\hline Non-married & $76(46.6 \%)$ & $347(29.2 \%)$ & $p<0.0001$ & $72(44.2 \%)$ & $p=0.66, n . s$ \\
\hline \multicolumn{6}{|l|}{ Education } \\
\hline Bachelor and above & $63(38.7 \%)$ & $585(49.2 \%)$ & $X^{2}(1, N=1351)=6.59$ & $77(47.2 \%)$ & $X^{2}(1, N=326)=4.17$ \\
\hline Trade/technical/vocational & $55(33.7 \%)$ & $320(26.9 \%)$ & $p<0.05$ & $39(23.9 \%)$ & $p=0.13$, n.s. \\
\hline training & $45(27.6 \%)$ & $283(23.8 \%)$ & & $47(28.8 \%)$ & \\
\hline High school or less & & & & & \\
\hline \multicolumn{6}{|l|}{ Relapsing-remitting MS } \\
\hline Yes & $69(42.3 \%)$ & $796(67.0 \%)$ & $X^{2}(1, N=1351)=5.56$ & $97(59.5 \%)$ & $X^{2}(1, N=326)=0.11$ \\
\hline No & $94(57.7 \%)$ & $392(33.0 \%)$ & $p<0.05$ & $66(40.5 \%)$ & $p=0.74$, n.s. \\
\hline MS severity & & & $t(1349)=-.51$ & & $t(324)=-1.25$ \\
\hline Mean (SD) & $2.91(1.16)$ & $2.86(1.10)$ & $p=0.61, n . s$. & $2.75(1.06)$ & $p=0.21, n . s$. \\
\hline Financial problem & & & $t(1349)=-3.76$ & & $t(324)=-0.83$ \\
\hline Mean (SD) & $1.75(0.71)$ & $1.52(0.72)$ & $p<0.0001$ & $1.68(0.78)$ & $p=0.41, n . s$. \\
\hline Health status & & & $t(1349)=3.02$ & & $t(324)=.62$ \\
\hline Mean (SD) & $2.62(0.93)$ & $2.86(0.96)$ & $p<0.01$ & $2.86(0.87)$ & $p=0.54$, n.s. \\
\hline
\end{tabular}

\section{Results}

\subsection{Propensity score matching}

PSM using logistic regression analysis and the nearest neighbor method was conducted to equalize the eight prominent covariates between Hispanic and Caucasian participants. The demographic information for the Hispanic and Caucasian groups before matching and after matching is presented in Table 1. As can be observed from Table 1, PSM analysis using the eight prominent covariates was able to identify 163 Caucasians who were a good match for the 163 Hispanics in the present study. Chi-square and $t$-test results indicated that there were no statistical differences on the eight prominent covariates between these two race/ethnicity groups after the PSM procedure.

A two-sample Hotelling's $T^{2}$ test was conducted on the three dependent variables of fair treatment, personal-environmental resources, and legal rights. The independent variable was race/ethnicity (Caucasian vs. Hispanic). Using Hotelling's trace as the criterion to evaluate all multivariate effects, the composite dependent variable was significantly affected by race/ethnicity, Hotelling's trace $=0.034$,
Table 2

Means and standard deviations of satisfaction for the Caucasian and Hispanic groups

\begin{tabular}{lcc}
\hline Factor & Caucasian & Hispanic \\
\hline Fair Treatment & $0.69(0.36)$ & $0.75(0.36)$ \\
Environmental/Personal Resources & $0.57(0.35)$ & $0.67(0.35)$ \\
Legal Rights & $0.47(0.39)$ & $0.61(0.42)$ \\
\hline
\end{tabular}

$F(3,242)=2.76, \quad p=0.043$. Univariate ANOVAs were conducted on each dependent measure separately to determine the locus of the statistically significant multivariate effect. There were two statistically significant univariate effects. First, Hispanics with MS had higher legal rights scores $(M=$ $0.61, S D=0.42)$ than Caucasians with MS $(M=0.47$, $S D=0.39), F(1,244)=7.95, p=0.005$. Second, Hispanics with MS had higher personal-environmental resources scores $(M=0.67, S D=0.35)$ than Caucasians with MS $(M=0.57, S D=0.35), F(1,244)=$ $4.72, p=0.031$. There was no difference between the two groups on fair treatment scores: Hispanics with MS $(M=0.75, S D=0.35)$; Caucasians with MS $(M=0.69, S D=0.36), F(1,244)=1.50, p=0.222$. Means and standard deviations for the three outcome variables for the Hispanic and Caucasian groups are presented in Table 2 . 


\section{Discussion}

The PSM procedure utilized in this study enabled the researchers to isolate the effects of racial/ ethnic status on participants' satisfaction with employment issues related to fair treatment, personal/ environmental resources, and legal rights. The two groups were equal with respect to the eight covariates that served as the basis for the PSM, which effectively controlled for any variability on the dependent measures that could be attributed to those factors.

At the most general level of analysis, on all three outcome measures, holding important demographic and disease-related covariates constant, Hispanics with MS were at least as satisfied with their employment situation as Caucasians with MS; moreover, Hispanics were more satisfied with the employment situation than the matched comparison group of Caucasians on the two sub-scales of legal rights and personal-environmental resources. In a recent study that compared Caucasians with MS to Hispanics and African Americans with MS without using PSM analysis to match sub-samples on important status covariates, Merchant et al. (in press) found Caucasians reporting higher levels of satisfaction with the employment situation than did non-Caucasians. Only by isolating the effects of race/ethnicity by matching groups on other potentially differentiating characteristics, as the researchers did in this study, did Hispanic people with MS emerge as more satisfied overall than their Caucasian counterparts.

\subsection{Fair treatment}

It is noteworthy that more than two-thirds of both groups (75\% of Hispanics and $69 \%$ of Caucasians) were satisfied on average with the items that constituted the Fair Treatment sub-scale. Even though only around half of the overall sample were employed for pay at the time of the national survey, both Hispanics and Caucasians expressed considerable satisfaction with the manner in which people with MS are treated in the workplace. It is perhaps especially important that these high satisfaction ratings were not influenced by race/ethnicity; the two matched groups did not statistically differ in their item means on this sub-scale.

One explanation for the non-significant betweengroup differences and the high satisfaction ratings on the Fair Treatment factor could lie in the high levels of education reported by both groups; nearly half of the sample held bachelor's degrees or higher. Highly educated workers, regardless of race/ethnicity, and perhaps regardless of disability status, tend to occupy high-status positions that are valued greatly by employers (Chan, 2016), and these individuals often have wide latitude to implement accommodations and other measures that enable them to be successful in the workplace. In those cases, workers often perceive their employers as treating them fairly, even preferentially, on the basis of their high-level employee status. Such may have been the case for respondents in this study.

These encouragingly high levels of perceived fair treatment on the part of both groups in this study bring with them important implications for clinical practice and rehabilitation research. It is imperative that rehabilitation counselors help Hispanics and Caucasians with MS maintain their high levels of satisfaction with the treatment they receive in the workplace. For people with MS who are currently employed, maintaining the bond they have with their employers can be facilitated by training in self-advocacy, non-adversarial decision-making, and effective procedures for requesting needed workplace accommodations (Nissen \& Rumrill, 2016). Should the important relationship between employee and employer be severed or strained, rehabilitation professionals can assist with consultation on worksite problem-solving, conflict resolution, and legal provisions that mandate equitable human resource policies and practices.

Given that this sample of people with MS was so highly educated, rehabilitation researchers are urged to examine the employment concerns and experiences of both Hispanics and Caucasians with MS who have lower levels of education and therefore may not experience such favorable treatment as was reported by the present respondents. Examining this population would allow stakeholders to gain a better understanding of the lived experiences and challenges that one with MS encounters having limited or lower levels of education, both in obtaining and maintaining employment. For example, one barrier that those with lower levels of education may face in employment could be lowered expectations from employers, which in turn could limit their opportunities for promotion and advancement, and lead to other microinequities or instances of unfair treatment or discrimination. This may especially be a barrier for those with MS who encounter functional limitations on the job. With their disability coupled with a lower level of education, employers' perceptions may be distorted and they may be more inclined to perceive employees' functional limitations as the 
results of personal shortcomings, and therefore fail to consider institutional barriers that may have prevented them from achieving higher education. In turn, these perceptions could lead to unfair treatment and employment discrimination (Roessler et al., 2011). Identifying and probing these barriers and considering other factors at play (such as the employee's race/ethnicity) could open the avenue for exploring potential solutions and how to implement and monitor them.

\subsection{Personal-environmental resources}

Within the Environmental/Personal Resources factor, averages of 67 percent of Hispanic respondents and 57 percent of Caucasians reported satisfaction with any given item. Hispanics reported significantly higher personal/environmental resources scores than did Caucasians. One possible explanation for this could be the collectivist, family-oriented nature of Hispanic cultures and the tendency to derive meaning from group membership rather than from individualism (Stone et al., 2007). These tendencies would be expected to lead to stronger familial and social bonds, which often serve as essential sources of support and encouragement, which in turn can also flow into one's overall perceptions of personal/environmental resources and positively impact her or his employment outlook. This may explain why Hispanic respondents, holding the demographic covariates constant, would outscore Caucasians on this dimension.

A review of the items in this factor shows that the resources with which Hispanics with MS were especially satisfied are directly within the scope of practice for rehabilitation counselors, who can directly provide workers with MS with resources to prepare for and overcome employment changes that may be necessitated by declining health over time (Murray, 2016). These include, for example, anticipating, identifying, and addressing vocational and environmental accessibility barriers - and preparing workers to understand their options and to communicate these effectively with their employers. In that endeavor, self-advocacy strategies to assist people with MS in maintaining their careers must be viewed as a critically important personal resource (Rumrill, 2016). Self-advocacy skills can be developed and exercised in many social support contexts such as MS support groups, families, caregivers, the NMSS, and MS clinics. People with MS can communicate openly and share their thoughts and desires with those they feel close to in their social support systems and collaborate with them to make important employment and overall treatment decisions. Further, with this social support network, the individual may feel more empowered and confident in her or his decisions, and also in the process of approaching the employer regarding the resolution of environmental accessibility barriers - which, depending on one's relationship with an employer, can be a difficult task (Roessler et al., 2016).

\subsection{Legal rights}

Significant differences were found on the Legal Rights factor between Hispanics and Caucasians with MS, with the former rating their satisfaction significantly higher (item mean 0.61) than the latter (item mean 0.47 ). The items associated with this factor primarily address the extent to which participants have knowledge of their employment rights and protections and disability benefits programs. These findings suggesting high levels of satisfaction with legal rights items on the part of Hispanics with MS oppose prior research (e.g., Rumrill et al., 2016) in which minoritized people with MS in general reported a lack of awareness of the ADA, the Family and Medical Leave Act, and Social Security Disability Insurance - as well as unfamiliarity with the process by which workplace accommodations are requested and implemented. Such was not the case for the well-educated Hispanic respondents who took part in this study, although the similarly well-educated Caucasians in this study expressed considerably lower levels of satisfaction with the items in this factor.

Whether helping a person with MS to maintain high levels of legal rights satisfaction or helping another to improve his or her understanding of those same issues, rehabilitation counselors must maintain a current working knowledge of legal protections that are available to people with MS and to minoritized individuals in the workplace. The ADA, the ADA Amendments Act (ADAAA), and the Equal Employment Opportunity Commission (EEOC) affirm the rights of all people with MS in employment settings (Roessler et al., 2007). People with MS need culturally relevant and accessible information about the ADAAA, the Family and Medical Leave Act, the Affordable Care Act, and Social Security provisions so they can make informed decisions about whether to continue in their careers as the illness progresses.

The Job Accommodation Network (JAN) is a helpful resource for people belonging to the broader 
disability community, and also for those with MS specifically. JAN provides clear and accessible information for both employers and employees regarding the job accommodation process, legal rights and requirements, and specific job accommodation options as mandated by the ADA. JAN offers a useful "A to Z" tab feature that filters job accommodations by disability, limitation, workrelated function, topic, and accommodation (JAN, 2020). An employee with MS can easily navigate the website and search job accommodation options and considerations specifically tailored to those with MS, or he or she could filter a specific MS-related limitation that is present on the job (such as fatigue or memory loss) and receive an individualized list of recommended accommodations.

The ADA Centers National Network also stands ready to assist people with disabilities, employers, and rehabilitation professionals with information, guidance, and training on the ADA and the ADAAA. In addition to the ADA and the ADAAA, the National Network specialists offer web-based and toll-free telephonic information on other disability laws such as the Fair Housing Act, Individuals with Disabilities in Education Act (IDEA), and Rehabilitation Act (ADA National Network, 2020). The National Network also provides a variety of training on a number of ADA topics such as accessible information technology, accessible architectural design, ADA and employment, and accessible healthcare. The trainings can be provided in-person or through distance technology such as webinars, podcasts, and online courses (ADA National Network, 2020). The National Network emphasizes that trainings are conducted at local, state, or regional levels and each training program is designed and tailored to meet the needs of each specific audience.

\subsection{COVID-19 implications}

One must consider the current employment and living situations for people with MS of both racial/ethnic groups in the era of COVID-19 when interpreting these results and their implications. COVID-19 poses an unprecedented threat to many people's health and lives, and many of the United States' stay-at-home orders have led to disruptions in daily life; social interactions; employment and activity participation; and increased fear, anxiety, and other negative emotions (Umucu \& Lee, 2020). Further, people with disabilities and racially/ethnically minoritized people are disproportionately affected both by the risk of contracting the virus (which can lead to increased stress and poorer health in and of itself) and by the stay-at-home orders and the effects they have on their employment, finances, and social supports. It can be expected that all three areas examined in this study (i.e., fair treatment, personal/environmental resources, legal rights) will continue to be impacted by COVID-19.

For example, in terms of personal/environmental resources, employed or soon-to-be-employed people with MS may have difficulty accessing and completing trainings that may be provided virtually by organizations due to their cognitive limitations and lack of face-to-face communication. Hispanics with MS may further face barriers that stem from linguistic inaccessibility of websites and application forms. Also, if people with MS are working remotely or virtually, they may have fewer social interactions and opportunities for bonding with their coworkers, which can also impact satisfaction with the overall employment situation. On the other hand, virtual trainings and even working remotely can be beneficial to people with MS, especially if physical accessibility and transportation issues were barriers prior to the coronavirus pandemic.

COVID-19 can also impact one's satisfaction regarding fair treatment. Whether an employee's job site has "gone remote" or has remained in-person, there may be significant modifications in the ways that employers communicate with and monitor their employees. One element of fair treatment is that employees with disabilities are evaluated no more frequently or no more critically than other employees. With the vast differences in communication and the way work is completed and carried out due to COVID-19, employers may be inclined to more closely monitor and evaluate their employees and their work output to gauge their adjustment to COVID-19-related changes. It is here that employers' negative biases or attitudes toward those with disabilities (such as MS) or racial/ethnic minoritized people (such as Hispanics) may manifest. For example, with the many physical, psychological, and social challenges that COVID-19 is presenting for many people, coupled with employees perhaps struggling to adapt to their adjusted work protocols, it might be expected that appraisals of job performance will decline. If an employee is a person from a racial/ethnic minoritized group or has a disability (or both) and her or his performance evaluations are deemed lower than usual, employers may attribute those changes more to the person's marginalized status rather than to the 
consequences of COVID-19. This may lead to unfair treatment and reduced opportunities on the job, or even demotions or terminations.

Legal rights may be the least of the three dependent variables impacted by COVID-19, at least in the sense of the provision of information. As mentioned, much information regarding disability laws and even training on those laws can be accessed virtually. But again, due to the changes in the ways that organizations operate due to COVID-19, some of the existing laws and their mandates may become complicated and unclear, or even change. These complications and changes, paired with potential lapses in communication between employees with disabilities and their employers, could lead to many negative consequences and misunderstandings regarding what rights people with disabilities have on the job amidst these unconventional circumstances.

\subsection{Limitations}

Several limitations of this study should be considered when interpreting our findings. These include the binary response set for items in the satisfaction scale, the low response rate (26\%) in the original survey from which this study's data were drawn (which limits the external validity or generalizability of the present findings), and the total reliance on self-report data for the covariates that were used in the PSM procedure. It is also true that this sample drawn from the membership organization NMSS may not be entirely representative of the broader population of Americans with MS. Finally, readers should note that findings from this study may not generalize to people with MS in countries outside of the United States.

\section{Conclusion}

This study has identified significant differences in the satisfaction that Hispanic Americans with MS and Caucasian Americans with MS ascribe to the overall employment situation in the areas of personal/environmental resources and legal rights. Hispanic participants in this study reported higher levels of satisfaction with employment issues in those two key areas. Although Hispanic respondents reported relatively high levels of satisfaction with the protection of their legal rights and their personal/environmental resources (and with their fair treatment in the workplace, for that matter), the fact that most Hispanic Americans with MS are unemployed warrants further inquiry to reconcile what seems to be an inconsistency between reported satisfaction levels and actual labor force participation. By understanding more fully the mechanisms that drive the choice to continue working or disengage from the workforce following MS onset or an MS diagnosis, as well as how those mechanisms are determined by the person's racial or ethnic membership status, rehabilitation professionals can ensure that employment-related interventions are grounded in the expressed needs and priorities of the growing population of Americans with MS.

\section{Conflict of interest}

None to report.

\section{Funding}

This research was funded partly through a Health Care Delivery and Policy Research grant from the National Multiple Sclerosis Society, New York, NY. The authors wish to thank the National Multiple Sclerosis Society, its participating chapters, and the study participants for their support and assistance with this research. This research was also supported by the Vocational Rehabilitation Technical Assistance Center on Targeted Communities grant (H264F150003) from the Department of Education. However, the ideas, opinions, and conclusions expressed do not necessarily represent the policy of the Department of Education, and endorsement by the Federal Government should not be assumed. Funding for this study was furthermore provided by the University Research Institute at The University of Texas at El Paso. The findings, interpretations, and presentation, however, were solely completed by the authors with no input received from the University Research Institute or The University of Texas at El Paso. Lastly, preparation of this article was partly funded by the United States Department of Labor, Office of Disability Employment Policy in the amount of \$3.5 million under Cooperative Agreement No. OD-32548-18-754-21. This document does not necessarily reflect the views or policies of the U.S. Department of Labor, nor does mention of trade names, commercial products, or organizations imply endorsement by the U.S. Government.

\section{References}

ADA National Network. (2020). Ask ADA questions. https://adata. org/technical-assistance 
Amezcua, L. (2014, June 8). Multiple sclerosis in the Latino/Hispanic American [PowerPoint slides]. Keck Medical School, University of Southern California. https://cdn.ymaws. com/www.mscare.org/resource/resmgr/2014amslides/Up dated-Amezcua_MS_in_Hispan.pdf

Bishop, M., Roessler, R. T., Rumrill, P. D., Sheppard-Jones, K., Frain, M., Waletich, B., \& Umeasiegbu, V. (2013). The relationship between housing accessibility variables and employment status among adults with multiple sclerosis. The Journal of Rehabilitation, 79(4), 4-14.

Buchanan, R. J., Zuniga, M. A., Carrillo-Zuniga, G., Chakravorty, B. J., Tyry, T., Moreau, R. L., \& Vollmer, T. (2011). A pilot study of Latinos with multiple sclerosis: Demographic, disease, mental health, and psychosocial characteristics. Journal of Social Work in Disability \& Rehabilitation, 10(4), 211-231. https://doi.org/10.1080/1536710X.2011.622959

Chan, R. Y. (2016). Understanding the purpose of higher education: An analysis of the economic and social benefits for completing a college degree. Journal of Education Policy, Planning and Administration, 6(5), 1-40.

Chiu, C.-Y., Chan, F., Bishop, M., da Silva Cardoso, E., \& O'Neill, J. (2013). State vocational rehabilitation services and employment in multiple sclerosis. Multiple Sclerosis Journal, 19(12), 1655-1664. https://doi.org/10.1177/13524585134 82372

Cristiano, E., Rojas, J. I., Romano, M., Frider, N., Machnicki, G., Giunta, D. H., Calegaro, D., Corona, T., Flores, J., Gracia, F., Macias-Islas, M., \& Correale, J. (2013). The epidemiology of multiple sclerosis in Latin America and the Caribbean: A systematic review. Multiple Sclerosis Journal, 19(7), 844-854. https://doi.org/10.1177/1352458512462918

Fraser, R. T., Clemmons, D., Gibbons, L., Koepnick, D., Getter, A., \& Johnson, E. (2009). Predictors of vocational stability in multiple sclerosis. Journal of Vocational Rehabilitation, 31(2), 129-135. https://doi.org/10.3233/JVR-2009-481

Job Accommodation Network. (2020). A to Z of Disabilities and Accommodations. https://askjan.org/

Julian, L. J., Vella, L., Vollmer, T., Hadjimichael, O., \& Mohr, D. C. (2008). Employment in multiple sclerosis: Exiting and reentering the work force. Journal of Neurology, 255, 1354-1360. https://doi.org/10.1007/s00415-008-0910-y

Koch, L. C., \& Rumrill, P. D., Jr. (2017). Rehabilitation counseling and emerging disabilities: Medical, psychosocial, and vocational aspects. Springer Publishing Company.

Merchant, W., Leslie, M., Li, J., Rumrill, P., \& Roessler, R. (in press). Racial/ethnic status as a differential indicator of employment concerns related to fair treatment, legal rights, and personal/environmental resources among people with multiple sclerosis. Journal of Rehabilitation.

Merchant, W. R., Li, J., Rumrill, P., Jr., \& Roessler, R. T. (2019). The factor structure of satisfaction ratings for selected employment concerns among people with multiple sclerosis. Journal of Vocational Rehabilitation, 51(1), 55-66. https://doi.org/ 10.3233/JVR-191025

Murray, T. J. (2016). The history of multiple sclerosis: From the age of description to the age of therapy. In B. S. Giesser (Ed.), Primer on multiple sclerosis (2nd ed., pp. 3-10). Oxford University Press.

National Multiple Sclerosis Society. (2019). MS prevalence. Retrieved May 23, 2019 from: http://www.nationalmssociety. org/About-the-Society/MS-Prevalence
Nissen, S. W., \& Rumrill, P. D., Jr. (2016). Employment and career development considerations. In B. S. Giesser (Ed.), Primer on multiple sclerosis (2nd ed., pp. 362-391). Oxford University Press.

Rivera, V. M. (2009). Multiple sclerosis in Latin America: Reality and challenge. Neuroepidemiology, 32(4), 294-295. https:// doi.org/10.1159/000204913

Rivera, V. M., \& Landero, S. (2005). Multiple sclerosis in Mexican American population. International Journal of MS Care, 7(4), 143-147. https://doi.org/10.7224/1537-2073-7.4.143

Rivera-Olmos, V. M., \& Avila, M. C. (2007). Multiple sclerosis in Latin America. Are McDonald's criteria really applicable? Revista Mexicana de Neurociencia, 8(1), 49-56.

Roessler, R., Hennessey, M., Neath, J., Rumrill, P., \& Nissen, S. (2011). The employment discrimination experiences of adults with multiple sclerosis. Journal of Rehabilitation, 77(1), 20-30.

Roessler, R. T., Neath, J., McMahon, B. T., \& Rumrill, P. D. (2007). Workplace discrimination outcomes and their predictive factors for adults with multiple sclerosis. Rehabilitation Counseling Bulletin, 50(3), 139-152. https://doi.org/10.1177/ 00343552070500030201

Roessler, R. T., Rumrill, P. D., Jr., Li, J., Daly, K., \& Anhalt, K. (2016). High priority employment concerns of Hispanics/Latinos with multiple sclerosis in the United States. Journal of Vocational Rehabilitation, 45(2), 121-131. https://doi.org/ 10.3233/JVR-160817

Rumrill, P. D. (2016). Return to work and job retention strategies for people with multiple sclerosis. In I. Z. Schultz \& R. J. Gatchel (Eds.), Handbook of return to work: From research to practice (545-561). Springer.

Rumrill, P. D., Jr., Roessler, R. T., Bishop, M., Li, J., \& Umeasiegbu, V. I. (2016). Perceived strengths and weaknesses in employment policies and practices among African Americans with multiple sclerosis. Journal of Rehabilitation, 82(1), 27-35.

Rumrill, P. D., Jr., Roessler, R. T., \& Koch, L. C. (1999). Surveying the employment concerns of people with multiple sclerosis: A participatory action research approach. Journal of Vocational Rehabilitation, 12(2), 75-82.

Rumrill, P. D., Jr., Roessler, R. T., Li, J., Daly, K., \& Leslie, M. (2015). The employment concerns of Americans with multiple sclerosis: Perspectives from a national sample. Work: A Journal of Prevention, Assessment, and Rehabilitation, 52, 735-748. https://doi.org/10.3233/WOR-152201

Smith, M. M., \& Arnett, P. A. (2005). Factors related to employment status changes in individuals with multiple sclerosis. Multiple Sclerosis Journal, 11(5), 602-609. https://doi.org/ 10.1191/1352458505ms1204oa

Stone, D. L., Stone-Romero, E. F., \& Lukaszewski, K. M. (2007). The impact of cultural values on the acceptance and effectiveness of human resource management policies and practices. Human Resource Management Review, 17(2), 152165. https://doi.org/10.1016/j.hrmr.2007.04.003

Umucu, E., \& Lee, B. (2020). Examining the impact of COVID-19 on stress and coping strategies in individuals with disabilities and chronic conditions. Rehabilitation Psychology. Advance online publication. http://dx.doi.org/10.1037/rep0000328

Vickers, M. H. (2012). Antenarratives to inform health care research: Exploring workplace illness disclosure for people with multiple sclerosis (MS). Journal of Health and Human Services Administration, 35(2), 170-206. 
Appendix A

The 17-item Satisfaction with Employment Issues Scale

\section{Fair Treatment}

- Are provided the same retirement benefits as other workers.

- Receive the same on-the-job training opportunities as other workers.

- Have their seniority honored in the same way as other employees.

- Are evaluated no more frequently than other workers.

\section{Environmental/Personal Resources}

- Have opportunities for job training or retraining.

- Are encouraged to take control of their lives.

- Have access to service providers who understand the needs of people with MS.

- Can expect employers to respond to their accommodation needs in a timely manner.

- Have physical access to workplace facilities.

- Are considered for other jobs in the same company if their MS prevents them from returning to their former jobs.

- Have access to assistive technology resources needed for work.

\section{Legal Rights}

- Have adequate information about benefits such as health and disability (short- and long-term) insurance.

- Have access to adequate information about Social Security programs.

- Understand the employment protections of Title I in the Americans with Disabilities Act as Amended (ADA).

- Know what to do if they encounter discrimination at work.

- Understand the risks and benefits of disclosing disability status to employers.

- Understand the health insurance provisions and protections of the Affordable Care Act (i.e., Obamacare). 